Canadian University Music Review

Revue de musique des universités canadiennes

\title{
Music Theory as Productivity
}

\section{Adam Krims}

Volume 20, numéro 2, 2000

URI : https://id.erudit.org/iderudit/1014455ar

DOI : https://doi.org/10.7202/1014455ar

Aller au sommaire du numéro

\section{Éditeur(s)}

Canadian University Music Society / Société de musique des universités canadiennes

\section{ISSN}

0710-0353 (imprimé)

2291-2436 (numérique)

Découvrir la revue

\section{Citer cet article}

Krims, A. (2000). Music Theory as Productivity. Canadian University Music Review / Revue de musique des universités canadiennes, 20(2), 16-30.

https://doi.org/10.7202/1014455ar
Résumé de l'article

The author here proposes Julia Kristeva's notion of "productivity" as a way of conceiving of the relations between different theories of music. By such a notion, rather than confirming, disconfirming, or exemplifying a theory, a particular musical work (or works) may redistribute the theory. The redistribution, in fact, might not only modify the initial theory-something certainly not original to productivity - but may also bring it into articulation with fundamentally opposed models of musical function, without which, nevertheless, the original theory remains incomplete. An extended example is adduced from Schubert's Schubert's Impromptu in G-flat Major, D. 899, in connection with, first, Schenker's Free Composition (Der freie Satz), and second, Schoenberg's Theory of Harmony (Harmonielehre); Schenker's inconsistent practice with respect to first-order neighbours, along with certain issues in the Impromptu, become the occasion for examining a case of productivity.
All Rights Reserved ( C Canadian University Music Society / Société de musique des universités canadiennes, 2000
Ce document est protégé par la loi sur le droit d'auteur. L'utilisation des services d'Érudit (y compris la reproduction) est assujettie à sa politique d'utilisation que vous pouvez consulter en ligne.

https://apropos.erudit.org/fr/usagers/politique-dutilisation/ 


\title{
MUSIC THEORY AS PRODUCTIVITY
}

\author{
Adam Krims
}

Recently, some music theorists and musicologists have been incorporating poststructuralism into their work, producing paradigms and problematics that had previously been rare in music scholarship. The list of musicologists engaging recent critical theory is, by now, quite vast, and in addition to well-known names like Susan McClary, Gary Tomlinson, Lawrence Kramer, and Richard Leppert, it also embraces newer (and different) scholarship. ${ }^{1}$ In the case of music theory, however, the ventures into post-structuralism have been more modest. Krims assembles some exceptional cases, to which one may add such ventures as David Schwarz, Richard Littlefield and David Neumeyer, and, depending on what one might consider "post-structuralist," perhaps several others as well. ${ }^{2}$

Many theorists appear to believe that abandoning the essentialist premise will either lead us into solipsism or somehow compromise the technical "advances" in the field. ${ }^{3}$ In fact, neither fear is justified, if developments in other fields can be taken as a cue. On the contrary, facing recent ideas about "structure," "work," and "text" (not to mention "context") is more likely to prevent solipsism, by enabling much broader communication with scholars outside our field. Solipsism is far more likely when we willingly accept methodological premises without serious examination.

As an illustration, it will be useful to invoke an idea from early ost-structuralist theory: "productivity," originally developed by Julia Kristeva and then adopted by Roland Barthes in the early 1970 s. ${ }^{4}$ An important difference between

\footnotetext{
${ }^{1}$ Susan McClary, "Paradigm Dissonances: Music Theory, Cultural Studies, Feminist Criticism," Perspectives of New Music 32, no. 1 (1994): 68-85; Gary Tomlinson, Music in Renaissance Magic: Toward a Historiography of Others (Chicago: University of Chicago Press, 1993); Lawrence Kramer, Classical Music and Postmodern Knowledge (Berkeley: University of California Press, 1995); Richard Leppert, The Sight of Sound: Music, Representation and the History of the Body (Berkeley: University of California Press, 1993).

2 Adam Krims, ed., Music/Ideology: Resisting the Aesthetic, Critical Voices in Art, Theory, and Culture (Amsterdam: G + B Arts International, 1998); Krims, "Bloom, Post-Structuralism(s), and Music Theory," Music Theory Online 0, no. 11 (1994); Krims, "On the Fear on Losing Our Tools: A Response to Joseph Straus," Music Theory Online 1, no. 1 (1995); David Schwartz, Listening Subjects: Music, Psychoanalysis, Culture (Durham and London: Duke University Press, 1997); Richard Littlefield and David Neumeyer, "Rewriting Schenker: Narrative-History-Ideology," Music Theory Spectrum 14, no. 1 (1992), 38-65.

${ }^{3}$ Pieter van den Toorn and Joseph Strauss both express this concern. Pieter van den Toorn, "A Response to Richard Taruskin's 'A Myth of the Twentieth Century,"' Music Theory Online 1, no. 5 (1995); Joseph Strauss, "Post-Structuralism and Music Theory:A Response to Adam Krims," Music Theory Online 1, no. 1 (1995).

${ }^{4}$ See Julia Kristeva, Desire in Language: A Semiotic Approach to Literature and Art, trans. Alice Jardine, Thomas A. Gora, and Léon S. Roudiez (New York: Columbia University Press, 1980); and The Kristeva Reader, ed. Toril Moi (New York: Columbia University Press, 1986).
} 
productivity and the kind of textual analysis usually practiced by music theory lies in the relationship between the musical work (or the score) and the analyst. In most contemporary music-theoretical works the music is treated as an object whose properties are to be discovered by a theoretical system. The theoretical system (whether it be pitch-class-set analysis, Schenkerian theory, serial theory, or whatever) is brought to bear on the piece, yielding information about that piece. If the piece manages somehow to instantiate the theory, then a mutual confirmation results: the theory is reinforced by its success at describing the piece, and the piece is praised for the masterful way in which it reflects the theory. ${ }^{5}$ Occasionally, pieces will cause the music theorist to modify her or his theoretical approach (as, say, some works of Milton Babbitt might be occasion for formalizing combinatorial possibilities ${ }^{6}$ ); but that case, too, lies within a model of mutual verification between theory and its objects.

The model requires that both the music and the theories be configured in a certain way. The musical work remains independent of the theorist's activity; its qualities are intrinsic to it, and it is the job of the music theorist to discover these qualities (or at least some of them). As for the theory, it must either be sufficient to describe some properties of the music (properties often deemed the most "essential") or must be modified to do so. If some aspects of the musical work seem to challenge the theory, then the challenge must be met either by making system and object jibe, or by modifying the system. (The bracketing off of social life from psychological interiority and ineffability of musical experience also act to support these procedures.)

The conception of music theory just described, while it has often produced interesting results, remains largely impervious to the critiques of essentialism and structuralism that have been developed in the last few decades. ${ }^{7}$ The alternative I would like to suggest is, in fact, only one aspect of Kristeva's much more involved exposition of productivity, although it is arguably the most influential. ${ }^{8}$ Reflecting my own biases, I wish to focus on the textualist, rather than the psychoanalytic or political aspects of productivity, though in my view they are ultimately inseparable, as I will discuss shortly. Also, I am leaving aside for

\footnotetext{
${ }^{5}$ In his article, "Schenker's Value-Judgments," Music Theory Online 1, no. 6 (1995), William Pastille points out that Schenker's later views explicitly instantiate the procedures described here.

${ }^{6}$ A case in point is Joseph Dubiel's three-part article, "Three Essays on Milton Babbitt," Perspectives of New Music 28, no. 2 (1990): 216-61;29, no. 1 (1991): 90-123; and 30, no. 1 (1992): 82-131.

${ }^{7}$ The literature on structuralism and essentialism is vast. A good introduction is provided by Robert Young, "Post-Structuralism:An Introduction," in Untying the Text:A Post-Structuralist Reader, ed. Robert Young (London: Routledge and Kegan Paul, 1981), 1-28. A locus classicus for an important critique of Saussurean semiotics is Jacques Derrida, Of Grammatology, trans. Gayatri Chakravorty Spivak (Baltimore: Johns Hopkins University Press, 1976). In "The Order of Discourse," among many other writings in his output, Michel Foucault portrays structuralist essentialism as the last form of an old tradition of textual exegesis (in Untying the Text, 48-78). In Philosophy and the Mirror of Nature (Princeton: Princeton University Press, 1979) and Consequences of Pragmatism (Minneapolis: Minnesota University Press, 1982), Richard Rorty provides some provocative philosophical elaborations. In Music/Ideology: Resisting the Aesthetic, Krims brings some of these critiques, especially those of Derrida, into contact with issues of music theory.

${ }^{8}$ Roland Barthes's own discussions of productivity seem to build on the aspects of productivity retained here. See Barthes, "Theory of the Text," in Untying the Text, 31-47.
} 
the moment her expositions of intertextuality and genotext/phenotext, even though they also figure prominently in her overall theory of productivity. ${ }^{9}$ In that sense the following is my own gloss on Kristeva. The focus here is on the relationship between a text, or for us, a musical work, and the theoretical apparatus we bring to bear on it. I would like to explore now the possibility that instead of confirming or modifying a theory, a musical work may redistribute the abstract frameworks that originally approach it.

By "redistribute," I mean that the process of analyzing a work may reconfigure, in some basic way, the methodologies that one brings to it; in that case, the relation between methodology and a particular interpretation is never stable. Here, I follow Kristeva's proposition that the reading subject may in fact enter into a productive relation with a text, in which the text engenders in the reader an unending process of contacts and mutual modifications-the text modifies the reader's subjectivity by becoming an intersection point for the numerous other texts that comprise that subjectivity. ${ }^{10}$ At the same time, the text provides the occasion for the undoing of the reader's stability, by putting into play new configurations of those texts that already have contributed to the subject's formation. More will be said about how productivity works toward the end of this essay; for the time being, it will be more instructive to produce a musical example to show how this redistribution could work.

Assuming some potential scope for productivity, a vast number of musical and music-theoretical "texts" should suffice to demonstrate its workings. For present purposes, I am interested to see how three texts might enter a productive relationship; those texts are Schubert's Impromptu in G-flat Major, D. 899, Heinrich Schenker's text Free Composition, and Arnold Schoenberg's Theory of Harmony. ${ }^{11}$

Before we engage those texts, some things should be noted about the selections. The first should be evident from the discussion so far, namely that they are not meant in any way to be representative of any particular approach;rather, they are meant to exemplify the notion that readings of texts-both theoretical and musical-may generally enter into relations of productivity. The second point that must be stressed here is that a reading of Schenker's Free Composition is just that - a reading of a particular text written at a particular time, and not necessarily a reading of the (related, but in many ways quite different) mainly North American tradition called "Schenker [or Schenkerian] analysis." The latter would, of course, be relevant to a broader study in which either the history of North American music theory, or, if one desired a more essentialist view of tonal music, a piece "in itself" was in question. Here, though-since the point is to narrow the focus strategically to a particular text-it would not only be irrelevant,

\footnotetext{
${ }^{9}$ See Kristeva, Desire in Language, and Moi, ed., The Kristeva Reader, as well as John Mowitt, Text:The Genealogy of an Antidisciplinary Object (Durham, N.C.: Duke University Press, 1992) for introductions to the concepts discussed here.

${ }^{10}$ See Kristeva, Desire in Language. In this sense, productivity is inseparable from Kristeva's theories of intertextuality.

${ }^{11}$ Heinrich Schenker, Free Composition, trans. Ernst Oster (New York: Longman, 1979); Arnold Schoenberg, Theory of Harmony, trans. Roy E. Carter (Berkeley:University of California Press, 1983).
} 
but it would in fact defeat the methodological purposes of the present study to turn Free Composition into that very different (which is not to say less worthwhile) object called "Schenker analysis"; we are interested here in seeing a localized interaction, whose broader implications will be sketched after the local contexts (i.e., the three sources at hand) have been considered. Similarly, a whole host of receptions of Schoenberg's treatise-whose history, of course, especially its recent history, is inseparable from that of Schenker analysis-are most worthy of attention in their own right, but will not be the focus here.

Rather, a direct engagement with the relevant piece and readings is not only desirable, but crucial; for the methodological premise here is that the three sources qua texts are permeable and productive in the sense just described. With no further ado, then, let us turn to an attempt to bring into dialogue two of the sources, namely Free Composition and the Schubert Impromptu.

I would like to posit an analytical situation, specifically that of a theorist who wishes to perform a Schenkerian graph of Schubert's Impromptu in G-flat Major, D. 899. I choose the Schenkerian method because it is, in my view, the closest thing that North America has to a naturalized music theory-that is to say, a theory of music that is often treated as an outgrowth not of history, but of natural properties of human beings and music. Example 1 shows my graph of the piece. Level $x$ is the foreground (or maybe a less deep middleground), level $y$ the deep middleground, and level $z$ the background. Let us posit for the moment that the piece is a ternary form (i.e., $\mathrm{ABA}^{\prime}$ ) with the sections starting at bars 1, 25, and 55, respectively. My graphs, then, attribute four middleground voice-leading stages to the B section. First, in bar 25 , the bass descends to $\mathrm{Eb}^{2}$, having descended from $\mathrm{Gb}^{2}$, while the upper voice remains on $\mathrm{Bb}_{b}^{4}$; the result is a root position $\mathrm{Eb}$ minor harmony, which is then tonicized. Second, in bars 25-34 an inner-voice $E b^{4}$ descends stepwise chromatically to $D b^{4}$, while the upper voice remains at $\mathrm{B}^{4}$ and the bass descends a major sixth from $\mathrm{Eb}^{2}$ to $\mathrm{G} b^{1}$. The net result is a motion from the root-position $\mathrm{Eb}$ minor triad to a root-position $\mathrm{G} b$ major triad. Third, bars 34-39 introduce a voice exchange in which $\mathrm{B} b^{4}$ moves to $\mathrm{Cb}_{b}^{4}$ as an octave-displaced neighbour, while the inner-voice $\mathrm{Db}_{b}^{4}$ crosses upwards to $\mathrm{E} b^{5}$. The bass supports the motion by moving to $\mathrm{C}^{2}$; thus, the $\mathrm{Gb}$ major triad formed at the second step has become the dominant of the now tonicized subdominant $\mathrm{Cb}$ major. Fourth, bars $40-55$ restore the neighboring $\mathrm{Cb}$ to its "obligatory register" and resolve it back to $\mathrm{B}^{4}$, while the inner voice alternates between $\mathrm{E}^{4}$ and $\mathrm{D}^{4}$ and the bass outlines motions within an $\mathrm{Eb}_{b}$ minor Stufe. And fifth, in the final moments of the B section (bars 51-54), the bass descends stepwise to $F^{1}$ and the upper voice moves to $C_{b}^{5}$ as a brief neighbour (recalling bars 32-39). Example 2 graphs just the $\mathrm{B}$ section, showing the motions just discussed, and restoring the notes to their abstractly "correct" registers.

According to my analysis, then, the upper voice undergoes three deepmiddleground motions in the B section: first, the Kopfton is restored to the middleground in bar 25 to begin the section; second, it moves to a neighbouring $\mathrm{Cb}^{5}$ (in the foreground, $\mathrm{Cb}^{4}$ ) in bars $32-39$; and third, it returns to $\mathrm{B} b^{4}$ in bar 42 , to remain there until the descent of the Urlinie. Most of the B section in the ternary form, then, "composés out" a complete upper neighbour to the Kopfton, 
Graph X

Bars:
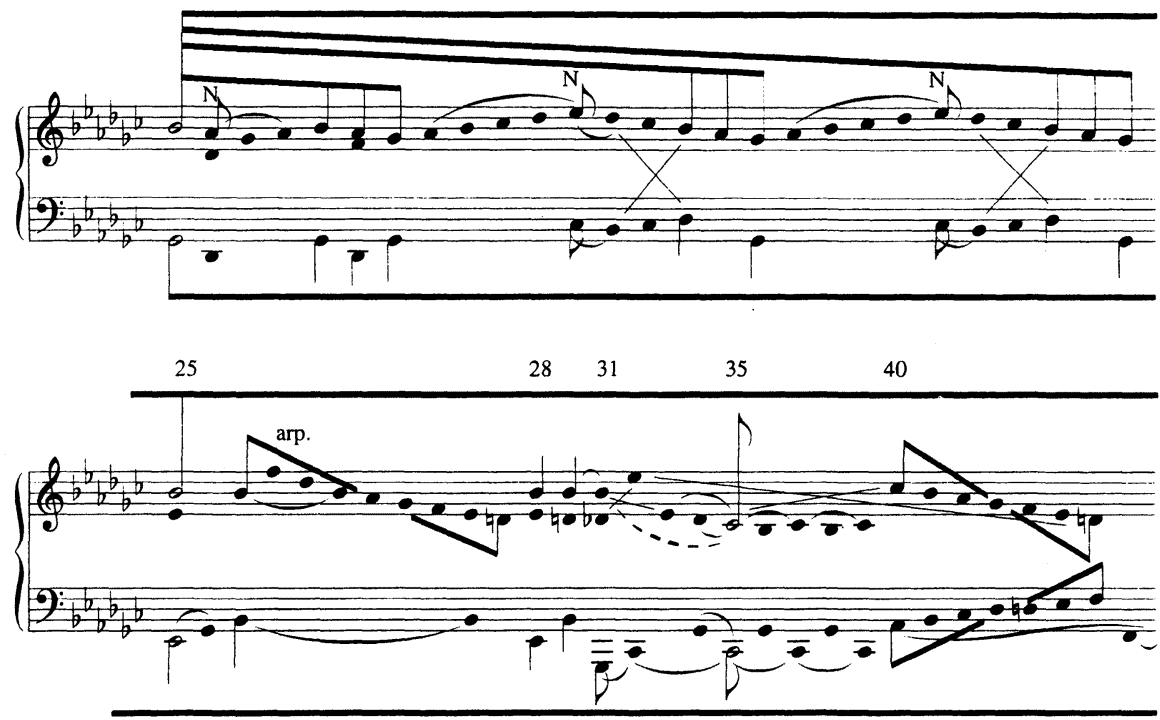

48

51

55

63

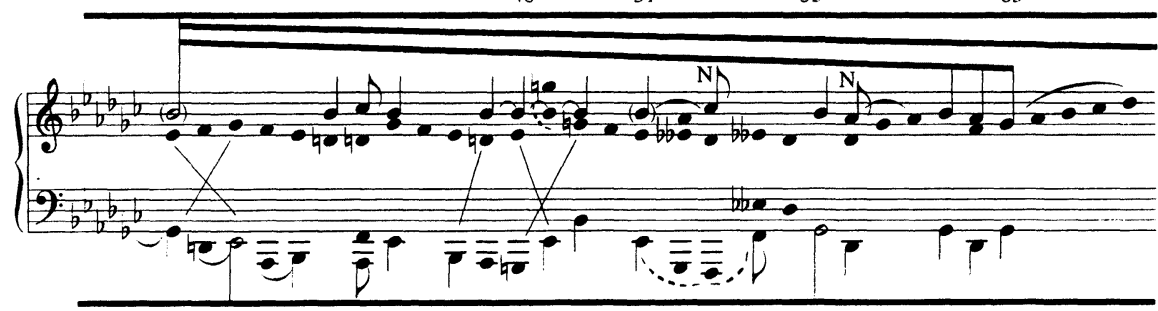

70

7374

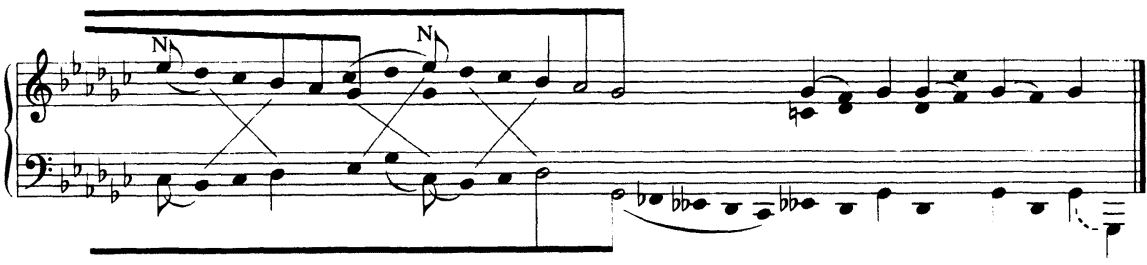

Example 1: Three graphs (X, Y, Z) of Franz Schubert, Impromptu in G-flat Major, D. 899 


\section{Example 1-Continued}

Graph Y
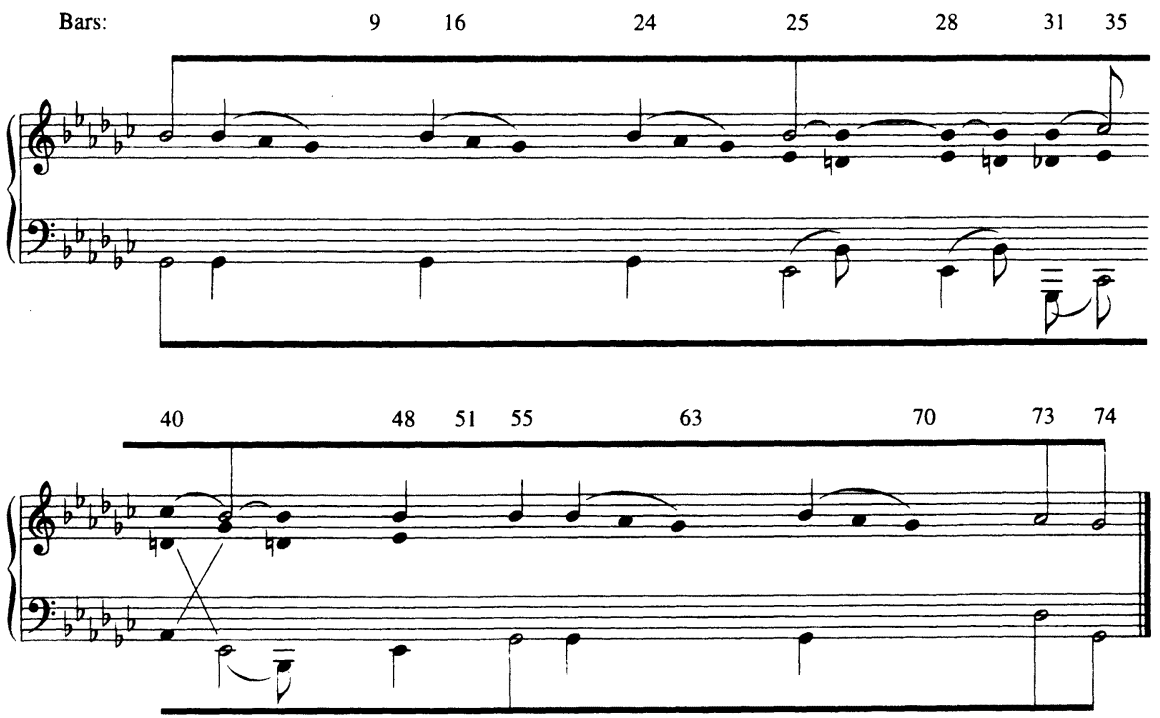

Graph Z

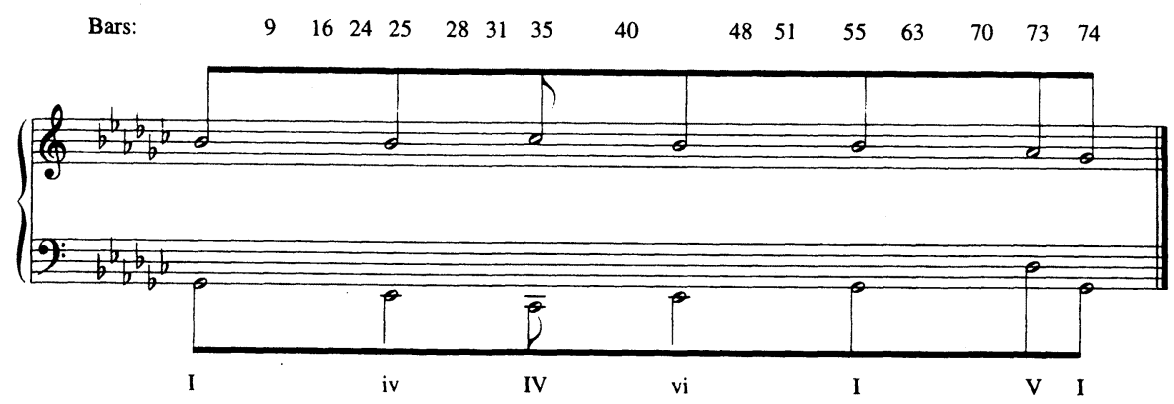

(N)

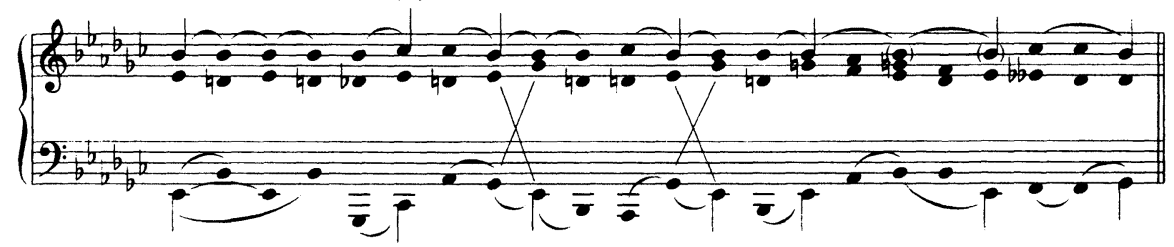

Example 2: Middleground graph of the B section of Franz Schubert, Impromptu in G-flat Major, D. 899 
and the $\mathrm{A}^{\prime}$ section then continues to compose out the $\mathrm{Bb}^{4}$, eventually allowing it to descend and complete the Urlinie.

Although $\mathrm{B} b{ }^{4}$ returns in the middleground in bar 44 according to these graphs, the end of the B section recalls the upper neighbour that had appeared earlier in the section. In bars 48-53, the middle voice stops alternating between $\mathrm{Eb}^{4}$ and $\mathrm{D}^{4}$, instead respelling $\mathrm{D}^{4}$ as $\mathrm{Eb}_{b^{4}}$ in bar 53 and leading it down to $\mathrm{Db}^{4}$ in bar 54 . The middle voice gesture is echoed emphatically in the foreground, when in bar 54 not only is the $E b_{b}^{4}$ to $\mathrm{Db}^{4}$ repeated, but it is doubled an octave below, while the upper and lower voices remain still. The neighbouring $\mathrm{C}_{b}^{5}$ is reflected in these graphs, but it is presented as a foreground, not a middleground, event. Thus it differs from the earlier neighbouring $\mathrm{C}_{b}^{5}$, which is graphed at a far higher level structurally.

But how could one justify the choice to graph the $\mathrm{C}^{5}$ of bars 32-39 in the background, while the following $\mathrm{C}_{5}^{5}$ in bars 53-54 remains a foreground event? After all, both are so-called "first-order" neighbours, meaning that they both elaborate an Urlinie tone. In response, one could cite the strong bass support for $\mathrm{C}_{b}^{3}$ in bars 32-39; the perfect authentic cadences in bars 34-35, 36-37, and 38-39; and the agogic accent on $\mathrm{Cb}^{3}$ (perhaps combined with its registral prominence) in bars 35-39. All of these factors support $\mathrm{Cb}^{4} \mathrm{~s}$ structural weight, but only within theoretical discourses not based directly on Schenker's writings. Presumably, the bass support for $\mathrm{C}_{b}^{3}$ is necessary but by no means sufficient argument for the background status of $\mathrm{Cb}^{4}$ (and even its necessity is probably more a product of Americanized Schenker practice than of Schenker's own practice). The perfect authentic cadence in bars 34-35 and the agogic accent in bars 35-39 both constitute that vague object we music theorists often call "stress" or "emphasis"; but in Schenkerian discourse, such things in themselves carry little weight (at least not acknowledged weight). They are "foreground" details, often acknowledged as interesting but ultimately not determinative of voiceleading and harmonic structure. So then, given two first-order neighbours, the one in bars 32-39 and the one in bars 53-54, why not graph them both with equal status?

It might be helpful to consult Free Composition in order to verify correct procedure. After all, Free Composition is often cited as the locus classicus for the groups of practices lumped under the term "Schenker analysis." A reason often cited for the treatise's status is the fact that it is a so-called "mature" work, and that it therefore reflects the highest level of refinement in Schenker's methods. Also, it is the place in which Schenker is the most thorough and explicit about some of his beliefs and methodologies. Unfortunately, the treatise complicates the interpretation of our neighbouring tones at least as much as it clarifies it.

By Schenker's own explicit discussion in Free Composition, a first-order neighbour is one of several possible ways to elaborate an Urlinie tone. ${ }^{12}$ As such, it should presumably have a similar status to the first-order $Z u g,{ }^{13}$ in other words,

\footnotetext{
${ }^{12}$ Schenker discusses the first-order neighbour in Free Composition, 42-43.

${ }^{13}$ Schenker discusses the first-order Zug in ibid., 44-46.
} 
both of these first-order events should have an equally "high" or "close to the background" status. In addition, any first-order neighbour should have a similar status, since it would always serve to delay the descent of the Urlinie. Certainly, some may be tonicized and others not (as in our Schubert example), but tonicization should not affect their functions (or status) as first-order neighbours. At the same time, some other aspects of Free Composition seem to question the equality we would expect. A reference to that treatise will illustrate.

In figures 153-3a and 153-3b of Free Composition, Schenker graphs a background and a foreground for Chopin's Etude, op. 10, no. 3. There, he considers the piece to compose out a three-line Urlinie, with a neighbouring $\mathrm{A}^{4}$ appearing in bars 22-53. He graphs the $\mathrm{A}^{4}$ with an open head, presumably indicating a status not far removed from the Ursatz. On one level, this is not surprising, since the $\mathrm{A}^{4}$ would be considered a first-order prolongation. On another level, though, Schenker's treatment of the neighbour note at hand is more puzzling. Nothing in Schenker's writings, here or elsewhere (as far as I know), would differentiate it in status from other first-order prolongations, for example Züge that originate with an Urlinie tone. Yet, the open head, the appearance in the background graph (exclusive of any other first-order prolongations), and the first level of Stufe-all seem to indicate that the neighbour-note formation discussed here somehow takes precedence over other first-order prolongations in the graph.

Even more puzzling, many of these other first-order prolongations are other first-order neighbours! These appear in bars $6,13,53$, and in an unmarked bar toward the end of the piece. But only the neighbour appearing in bar 53 is admitted to the background graph and given a Stufe label at the highest level. Its high level could not be attributed to foreground stability; in fact, all the other first-order neighbours are tonicized, while the "background" neighbour alone appears as a dissonant seventh over a dominant harmony. Thus, not only does Schenker often seem to emphasize first-order neighbours over other firstorder elaborations, he also makes clear that not all first-order neighbours are created equal. And the inequality does not seem to hinge on the issue of consonant support.

One possible explanation is the graph's appearance in a section on form. Perhaps the prominence accorded this neighbour-note is for the sake of demonstrating how such upper neighbours to Urlinie notes can create ternary form. (And in fact, it is one of the examples used to illustrate neighbours as creators of form. ${ }^{14}$ ) But there are two problems with our proposed explanation. One problem is that it seems to imply that the graphs in Free Composition may frequently be mixed in purpose; they may sometimes reflect as much a local pedagogical point as the "method" later referred to as "Schenker analysis." It is problematic not because it is false, but precisely because it appears in many cases to be true, a fact rarely discussed about Free Composition.

A second problem with the explanation is that the relevant section of Free Composition is not the only one in which Schenker treats some first-order neighbour

${ }^{14}$ Ibid., 132-33. 
notes in the fashion described. In fact, quite consistently throughout the treatise, Schenker graphs some first-order neighbour notes as if they were somehow "higher" in status (or "deeper") than other first-order prolongations, while his prose seems to indicate that all first-order prolongations should be of equal status. In Free Composition, many first-order neighbour notes tend to be graphed in a manner suggesting background status: they are represented by open heads, often beamed along with the Ursatz. In addition, when Schenker provides Roman numerals below graphs indicating the highest-level Stufe, very often the only non-Urlinie tone to receive its own high-level Stufe is a first-order neighbouring tone. This may be seen, for example, in another graph from Free Composition, the one of Chopin's Polonaise, op. 26, no. 1 (figure 44, no. 2); here we can see a similar unexplained emphasis on the first-order neighbour, by all the criteria just mentioned. ${ }^{15}$

The confusion is compounded by the fact that Schenker does not tell us why his graphing and Stufe labeling seem to show such preference for some firstorder neighbours. ${ }^{16}$ What, then, could account for the odd priority about which he is so silent? Are we seeing an unwitting (or at least unadmitted) concession to traditional notions of form? If voice-leading is ontologically prior to form, then why would an aspect of formal design infringe upon the graphing of voiceleading levels? ${ }^{17}$ The questions seem particularly pertinent since, after all, it would have been perfectly easy for Schenker to graph these neighbour notes analogously to first-order Züge, or equally to each other, and to assign their Stufen similar status. He could even have emphasized their contribution to formal design without resorting to the graphing methods just described. Why did he so consistently graph and label as we have seen him do?

It is difficult not to perceive a confrontation here, a place at which Schenker's languages-prose and graphic-come to an impasse. The impasse is not necessarily a rebuke of Schenker: it is difficult to imagine a theory that does not at some point rely partially on its own negation. It is rather to underline that "Schenker analysis"-which, certainly, is far more diverse than anything that could be derived solely from Free Composition-may be, from its inception, a more problematic object than we care to think. ${ }^{18}$

We may be tempted to respond by trying to "clean up" Schenker: we could always adjust our own graphing techniques and Stufe labels in order to reflect more consistently the hierarchies prescribed in Schenker's prose. ${ }^{19}$ The "cleaning

${ }^{15}$ Other examples in Free Composition that most clearly show a preference for neighbouring formations are fig. 22 a; fig. 76 , no. 5 ; fig. 99 , no. 2 ; fig. 102 , no. 2 ; fig. 107 ; fig. 119 , no. 21 ; fig. 152 , no. 5 ; fig. 153 , no. 1 ; fig. 154 , no. 5 a; fig. 155 , no. 1 ; fig. no. 2 ; and fig. 156 , no. 1 .

${ }^{16}$ And the confusion is compounded by the graph's being partially metricized. I am grateful to David Lewin for raising this point to me.

${ }^{17}$ Schenker is clear about the priority of voice-leading (Free Composition, 130-31 and 133-37, among other places).

18 Richard Cohn discusses, instructively, other relevant issues with respect to the autonomy of motives in Schenkerian practice. See "The Autonomy of Motives in Schenkerian Accounts of Tonal Music," Music Theory Spectrum 14, no. 2 (1992): 150-70.

${ }^{19}$ Matthew Brown attempts just such a cleaning, with some interesting results. See his "A Rational Reconstruction of Schenkerian Theory" (Ph.D. diss., Cornell University, 1989). 
up," though, could not be any more than a motivated choice to prefer one strand of Schenker's mature work over another; we could do it, if we wish to reflect our own concern, but we would have a hard time saying that we are approaching any "truer" or "purer" version of Schenker analysis. Without making such a choice, though, we are left with "Schenker analysis" as a fundamentally heterogeneous object.

Graphing Schubert's piece as I have, then, positions us in relation not only to Free Composition (and possibly other writings of Schenker) but also a dense tradition of (mainly North American) Schenker interpretation. Choosing a privilege for the initial $\mathrm{Cb}_{5}^{5}$ configures Schenker in a definable way, following his graphic practice despite his prose: we do as he does, not as he says. At the same time, and in an inseparable gesture, our analytic production configures the Impromptu in a definable way: the initial first-order neighbour is now admitted to the highest structural level, and the formal design (again, in a traditional sense of "form") penetrates to the background. We have now a "fundamentally" ternary piece, whose three-part articulation is part of its most basic voice-leading structure. At the same time, the second first-order neighbour, that which ends the B section, remains a relatively foreground elaboration.

But the decision to follow Schenker's graphic technique does not entirely solve our problem. Analyzing some first-order neighbours in such a way invokes notions that remain unexplained, since Schenker's endorsement of the practice is silent. The desire to theorize explicitly the status of $\mathrm{C}_{5}^{5}$-as presumably a music theorist should do-then opens a floodgate to other discourses of tonal music, many of which are more explicit on the issue than Schenker.

Free Composition does not tell us where to look for another theory of tonality to fill the gap; the choice will not be systematic with respect to "Schenker analysis." And yet the choice must be made, in order for our graph to be complete. We are no more likely to look toward Schoenberg than toward Riemann, Fétis, or Hindemith. Still, in our particular case, Schoenberg offers an interesting perspective on tonality that could help us be more explicit about our firstorder neighbour. For the Schoenberg of the Harmonielehre, bars 33-39 constitute a move to the subdominant region. Not only is the move highly articulated in the ways just discussed, but also any move to the subdominant key would in itself be notable. The tonic, for Schoenberg, is always in danger of slipping to the subdominant key; and the danger, in turn, results from the tendency of any major chord to become "lost" in its lower fifth. ${ }^{20}$ The slippage to the subdominant is not simply one among many features of tonality for Schoenberg; it is one of tonality's cardinal features. In fact, Schoenberg goes so far as to explain the subdominant's threat as the rationale behind the authentic cadence: the leading tone of the tonic, the only note the tonic does not share with its subdominant, is present in the cadence precisely to overcome the danger of subdominant slippage. ${ }^{21}$ The tonic's tendency to become the dominant of its

\footnotetext{
${ }^{20}$ See Schoenberg, Theory of Harmony, esp. 129-30,150-54,185, and 219.

${ }^{21}$ Ibid., 129-30. The scale degree $\hat{4}$ is analogously present in $V^{7}$ to counteract any ambiguity between the tonic and its dominant. But Schoenberg does not consider its presence the principal matter of key definition, which remains the protection of the tonic from its "lower fifth," or subdominant.
} 
subdominant is one of the forces against which a composer always struggles, in tonal contexts.

Thus, any modulation to the subdominant, such as that within bars 31-35, would have a dual significance for Schoenberg. First, it would confirm the tendency of the tonic to bring about its own subdominant and thus instantiate one of his basic attributes of tonality. Second, and perhaps more important, the modulation will establish a threat to the tonal unity of the piece-a threat that must be overcome if the tonic is to predominate. ${ }^{22}$ The ultimate victory of the tonic is mandatory in Schoenberg's view (at least for music from this period); and its assurance involves balancing the heavy emphasis on the subdominant region with an emphasis on the dominant region. From Schoenberg's perspective, then, the rest of the piece may be seen as playing out the need for regional balance. One could state that the balance is restored with the dramatic approach to the dominant in bars 51-54, in which case the doubled inner-voice motions to $\mathrm{D} b$ in bar 54 would acquire more significance than in the Schenker graph. One could bolster the point by emphasizing that the analogous place in the $\mathrm{A}^{\prime}$ section (bars 74-82) also approaches the dominant in an emphatic fashion. (These places would seem the best candidates for dominant-region emphasis, since there is no dominant key area to be found.) The regional balance would then be confirmed in bars $82-86$ by the continual repetition of the progression $\left[\mathrm{V}^{7}-\mathrm{I}\right]$ (without any hint left of the subdominant region).

But these new structurings are not consistent with the ones created by the Schenker graph. Granted, the subdominant key area was central to the Schoenbergian interpretation, as it was (though perhaps less so) to the Schenkerian interpretation. But the emphatic approaches to the dominant in bars 51-54 and 74-82, so crucial to the narrative of the regions, are effectively bracketed in the Schenker graph. There, bars 51-54 present an octave transfer in the bass and a relatively low-level neighbour in the upper voice. And bars 74-82 only elaborate in the foreground the Urlinie note's arrival in the background. Similarly, whereas bars $82-86$ in the Schoenberg interpretation served to secure the restoration of regional balance, in the Schenker graph they only prolong the final scale degree 1. More basically, Schoenberg's notion that a tonic is fundamentally unstable, would be heretical to a Schenkerian outlook, for which the tonic is always present and always generative of an entire piece. ${ }^{23}$

It should be kept in mind, though, that the whole narrative of regional bal-

${ }^{22}$ Schoenberg discusses the struggle between key areas in revealingly and suggestively political language in Theory of Harmony, 150-53. The underlining of the subdominant region in bars 31-39 could also be said to emphasize the earlier modulation to $\mathrm{Eb}$ minor in bars 25-30. Bars 31-39 would acquire more significance as a "neutral" region in transition from the tonic to the subdominant region; in the Schenker graph, bars 31-39 formed a relatively low-level arpeggiation in the bass from scale degree to scale degree.

${ }^{23}$ One could attempt a fusion of Schenkerian and Schoenbergian approaches by pointing out that the background graph in fact arpeggiates the subdominant in the bass. The arpeggiation might then be used to argue that the Schenkerian analysis does, in fact, reflect a slippage to the subdominant. But the argument would hardly be less heretical in Schenkerian discourse. 
ance entered our discussion precisely because of the unexplained Schenkerian preference for certain first-order neighbours. The preference had to be abandoned, left unexplained-or theorized. But theorizing the preference forced us to look outside Schenkerian theory. We started the analysis with the closest thing that contemporary North American music theory has to a naturalized discourse about tonal theory-Schenker analysis-and quickly encountered a point of insufficient explanation. As theory, presumably, abhors a vacuum, we have had to resort to another theory which would justify an act already performed in the name of Schenker. That second theory, in turn, required us to structure the Impromptu in yet other ways that now challenge our original analysis. Here, the workings of productivity come into better focus and the word "redistributive" can be further explained.

For Kristeva, symbolic systems (of which music theories are every bit as much an example as language) are always incomplete representations of subjectivity, whose drives and physicality are not representable symbolically. ${ }^{24}$ While not invalidating symbolic systems entirely, the insufficiency of symbolic systems does situate them in a relation of tension with the subject. Textuality is a mode of reading that foregrounds that tension, by allowing the text to redistribute the order of symbolic systems. If a text can redistribute what had seemed like a stable symbolic order, then that order's relative, dynamic, and contingent status is made visible. The text then ceases to be a stable site of intrinsic meaning; rather,

The text is ... a productivity, and this means ... that its relationship to the language in which it is situated is redistributive (deconstructive-constructive). ${ }^{25}$

The word "text" here does not necessarily refer to a literary text in the traditional sense; a musical work can just as easily be a text as King Lear, a television commercial, or a political speech. ${ }^{26}$ "Text," here, refers most generally to any cultural object we may encounter and whose workings we may wish to theorize. Tzvetan Todorov, in his summary of productivity, is explicit about its effects:

[T] he text, in the rigor of its practice, redistributes ... [T] he text does more than rework; for it substitutes for the very idea of predetermining laws ... that of an order whose interdependent parts "get the upper hand successively in different conditions of use," of a network of multiple connections with variable hierarchies. ${ }^{27}$

Instead of predetermined laws such as Züge or Stufen, we have encountered

${ }^{24}$ Much of the following exposition is taken from Kristeva, Desire in Language, 92-123 and Mowitt, Text,104-16.

${ }^{25}$ Kristeva, Desire in Language, 36.

${ }^{26}$ Ivanka Stoïanova applies Kristevan notions of "text" to music. See Geste, texte, musique (Paris: Union générale d'éditions, 1978).

${ }^{27}$ Oswald Ducrot and Tzvetan Todorov, Encyclopedic Dictionary of the Sciences of Language, trans. Catherine Porter (Baltimore: Johns Hopkins University Press, 1979), 358-59. 
an order where Schoenberg at least temporarily (but never ultimately) "gets the upper hand." A text seen as a productivity, then, is responsible for reconfiguring the discourses which describe it and which, presumably, it embodies. If, in Kristeva's words, the text "redistributes the order of language," 28 then a confrontation with a text never leaves us in the same relationship to discourses as that with which we started. A function of textuality, then, is its ability to critique and reconfigure whichever symbolic systems we had initially regarded as stable and reliable. ${ }^{29}$ These "symbolic systems" would include theories of music as discourses-in other words, as ways in which we produce, validate, and distribute bodies of knowledge. ${ }^{30}$ And the reconfiguration is both internal to the discourses (as when Schenker is set against himself on the issue of first-order neighbours) and also interdiscursive (as when Schoenberg is brought to the rescue).

It is important to note that the reconfiguration does not result from any "internal" or "essential" property of the Impromptu, but rather from a certain mode of reading it. In other words, not the piece, but an aspect of Schenkerian analysis, along with an aspect of Schoenberg's notion of tonality, brought about the productivity. The particular modes of reading - and the desire to theorize the music-set productivity in motion. It is also important to note that we have not simply produced a "pluralistic" or "dualistic" reading of the piece, because the discourses we have engaged do not allow a stable combination. Schoenberg's regions assert the instability of the tonic and set the subdominant as at least the equal of the dominant in generating tonality. But if we accept his view (which we must do if we are to avail ourselves of the regions), then we destabilize the Schenkerian project: for Schenker, the tonic is stable and the subdominant is secondary to the ultimate V-I cadence. True, the particular conflict with Schenker results from the choice of Schoenberg to support the first-order neighbour; but whichever other theorist of tonal music we might choose would eventually collide with Schenker in some fundamental way. Thus, the activity we call "Schenker analysis" is divided from within, and multiplied in its portrayal of some basic aspects of tonality: it has been reconfigured. The Impromptu, too, has been reconfigured: its three-part structure (or, in the Schenkerian discourse, its firstorder neighbour) has been maintained only by pluralizing the tonality it supposedly embodies.

Although the Impromptu is only one musical text, the mode of reading that was enacted is in no way dependent upon the particularity of the piece; in fact, from the standpoint of the issues raised here, the Impromptu is far from exceptional. What is exceptional, at least in the current stage of music-theoretical history, is a willingness and ambition to allow the internal instabilities and in-

\footnotetext{
${ }^{28}$ Kristeva, Desire in Language, 36.

${ }^{29}$ Mowitt describes this aspect of Kristeva's productivity in Text, 104-10.

30 "Discourse" is, of course, a term more familiar from the works of Foucault; but Kristeva's discussion embraces the whole of symbolic practices, so that the term "discourse," while anachronistic, is not entirely out of place here.
} 
tersections of tonal theories to bring about a productivity. Such an approach could not completely displace traditional music theory; on the contrary, it is dependent on developed theories for its operation. In fact, textualist approaches tend to encourage a proliferation of discourses: in Kristeva's words, "[textuality] postulate[s], not a beyond to representation, but a transfusing and renewal of it." 31

Two more aspects of the preceding discussion are worth pointing out. First of all, the attempt at a Schenker graph has turned out to efface the difference often assumed between music theory and metatheoretical work. The instability of Schenker analysis required, at some point, a turn to another model of tonality; the other model, then, forced us to theorize the relationship to the original model. Thus, what are often considered "metatheoretical" considerations turned out to be crucial to the most "concrete" music-theoretical act-analyzing of the "structure" of a piece. Effacing the dichotomy between the theoretical and the metatheoretical is a gesture indigenous to post-structuralist work, dating back at least to Lacan's early critiques of metalanguage. Once the dichotomy is allowed to break down, critical theory becomes music theory, and vice versa.

Further along the path, we may engage not only textualist work but also, among many other things, cultural dialogics. Of the Tel Quel group, Kristeva incorporated the dialogics of Bahktin to a greater extent than most, and quite explicitly. ${ }^{32} \mathrm{I}$ have spoken elsewhere of how cultural dialogics can be of use in theorizing hip-hop. ${ }^{33}$ It would seem that a dialogics of musical objects would also hold great promise for describing what we are doing with music theory. Since the theories we design generally create musical objects with plural cultural and historical inscriptions, as music theorists we are constantly creating cultural dialogues. These dialogues, in turn, constitute new musical objects, musical works of the past continually refashioned in our own image.

When I say that we are not discovering essences but rather refashioning older music in our image, I am not belittling what we do as music theorists. On the contrary, I believe that this continual rewriting of music is extremely important, at least as valuable as discovering essences could possibly have been, and probably more useful. If it makes sense to talk of a "living culture of the past," then productivity and dialogue would seem to be a valuable way to describe it.

\begin{abstract}
The author here proposes Julia Kristeva's notion of "productivity" as a way of conceiving of the relations between different theories of music. By such a notion, rather than confirming, disconfirming, or exemplifying a theory, a particular musical work (or works) may redistribute the theory. The redistribution, in fact, might not only modify the initial theory-something certainly not original

\footnotetext{
${ }^{31}$ Kristeva, Desire in Language, 113.

${ }^{32}$ See ibid., 64-91 and 159-209.

33 "Gangsta Rap and Cultural Dialogics," paper delivered to the Fifth Congress of the Interna-
} tional Association for Semiotic Studies, Berkeley, California, 1994.
\end{abstract}


to productivity - but may also bring it into articulation with fundamentally opposed models of musical function, without which, nevertheless, the original theory remains incomplete. An extended example is adduced from Schubert's Schubert's Impromptu in G-flat Major, D. 899, in connection with, first, Schenker's Free Composition (Der freie Satz), and second, Schoenberg's Theory of Harmony (Harmonielehre); Schenker's inconsistent practice with respect to first-order neighbours, along with certain issues in the Impromptu, become the occasion for examining a case of productivity. 